\title{
Editorials
}

\section{Can technology help reduce risk of harm in patients with epilepsy?}

\section{EPILEPSY MORTALITY AND CLINICAL GOVERNANCE}

Sudden unexpected death in epilepsy (SUDEP) is possibly the most common cause of death as a result of complications from epilepsy, accounting for between $7.5 \%$ to $17 \%$ of all epilepsy-related deaths ${ }^{1}$ and $50 \%$ of all deaths in refractory epilepsy. ${ }^{2}$ The UK has 600000 people with epilepsy (PWE), 30\% being treatment resistant. Sudden death is 20-fold higher in PWE than the general population. Epilepsy is the fifth highest cause of life-years lost in men and eighth in women in the UK. The public health burden of SUDEP alone is estimated as second only to stroke among neurological conditions. ${ }^{3}$

Forty-two per cent of all deaths are considered avoidable. ${ }^{4}$ Consequently, the National Institute for Health and Care Excellence (NICE) epilepsy guidelines in 2004 and $2012^{5}$ recommend discussion of SUDEP with newly-diagnosed PWE. This is rarely delivered and until recently only $4 \%$ of PWE had a recorded SUDEP discussion. ${ }^{6}$

In their current publication of the NHS Outcomes Framework, the government prioritises the prevention of amenable mortality, making it a core focus for NHS services. Epilepsy mortality features in new NICE Standards as well as NICE Clinical Guidelines. ${ }^{5}$ However, the dilemma remains of when, where, how, and what to discuss about epilepsy risk, especially SUDEP. Further to the discussion there is a lack of a structured monitoring of risk especially in primary care. Meaningful management of SUDEP risk in particular, and epilepsy risk in general, is arbitrary, non-person centred and with no evidenced mechanism.

In clinical practice, especially in primary care, the lack of any tools to support risk management is of concern. Risk management has been highlighted as vitally important to reducing avoidable epilepsy-related deaths, both in research and reporting but also via Prevention of Future Death reports and Fatal Accident Inquiries held by those investigating sudden and unexpected deaths. A central theme of all these reports is a lack of awareness or underestimation of risk. In some places a myth that was widespread in the 1990s persists that seizures are benign.

SUDEP occurs today in the context of the removal of epilepsy indicators from Quality Outcome Framework (QOF) in primary care and pressures in hospitals to discharge

"EpSMon looks to incorporate key evidence-based risk factors with a view to empowering service users to monitor their own risk

patients early, impacting on the care for those with epilepsy. PWE want information on risk. ${ }^{8}$

There is a substantial body of work on SUDEP risk. 9.10 While no definitive mechanism or factors have been categorically identified, research has shown that there are various factors that can influence risk of an adverse outcome. However, this has not been brought together in a systemic manner to help patients and clinicians have a personcentred discussion of individual risk.

The problem requires a solution that is evidenced based, simple to use in a clinical setting, easily adoptable across a range of settings and practices, and supportive of communicating to patients and/or their carers clear outcomes for change. It also needs to be modifiable to change and lend itself to a range of applications. Importantly, if achievable, it needs to be patient led.

\section{SUDEP AND SEIZURE SAFETY CHECK LIST DEVELOPMENT}

A detailed literature review ${ }^{9}$ was undertaken to determine SUDEP contributory risk factors. A total of 18 factors were identified, of which 11 were deemed modifiable and with the potential to influence the SUDEP risk. A SUDEP safety checklist ${ }^{9,10}$ to help communicate and quantify risk was postulated taking account of the epilepsy, psychological, social, and biological factors. The checklist supports the goal of patient safety by focusing on the modifiable factors to guide treatment. It is also a tool to open a person-centred discussion with PWE to outline how individual behaviours impact on risk (for example, lack of compliance or alcohol misusel and to encourage therapeutic engagement.

The checklist was used as the data collecting tool for a retrospective SUDEP study, incidentally the largest epidemiological study for SUDEP in England. ${ }^{11}$ It helped confirm risk factors for worsening of epilepsy control and SUDEP. In about 90\% of the SUDEPs there was a noted increase in seizure frequency and/or intensity
3-6 months before death, but poor contact with primary or secondary care. The study highlighted presence of modifiable risk factors 3-6 months prior to demise, which going uncorrected had a potential cumulative effect on seizure control and risk.

\section{FEEDBACK ON CHECKLIST IN ROUTINE PRACTICE}

The checklist has been in use for 2 years as routine practice in epilepsy clinics in Cornwall, with feedback from over 200 PWE and/or their carers. Ninety-eight per cent responded positively, and $2 \%$ were neutral for the quality of consultation provided using the checklist. High scorers on the checklist said it made them think of issues to address and modify especially with lifestyle choices. Those with low scores and those who were previously aware of SUDEP said it was a relief to be discussed. In June 2014 to June 2015 approximately $80 \%$ of PWE accessing Cornwall epilepsy services have had their SUDEP risk assessed and recorded.

A 12-month telehealth pilot in a large GP primary care service initiated proactive checks using the checklist on 15 high risk PWE, all defined as having treatmentresistant seizures for $>10$ years but stable in the community. Every 3 months a telehealth practitioner called up the registered patients and conducted the checklist with them. All results were then communicated to the GP in a timely way. Telehealth services, in what was considered a stable 'at risk' population, led to $17 \%$ receiving several interventions in the previous year that would not have happened without the tool. Clinicians across primary and secondary care have reported that this is working well as an intervention to raise awareness and improves the management of high-risk patients; proving a useful system for clinicians and an improvement on previous clinical practice.

There is still ongoing debate about the need and value of informing PWE of SUDEP, 12 however our work challenges this view. A structured approach pays dividends in focusing individuals on items in their locus of 


\section{"The checklist and EpSMon are part of the new Epilepsy Commissioning Tool kit ... In addition to improving care it could also provide a cost-effective model to fill the safety void left from the recent removal of the QOF in epilepsy in primary care.}

control. There is developing local evidence of improving safety by indicators of accident and emergency admissions, clinicians, patients and carer feedback, and SUDEP reduction.

Changing cultural stereotypes takes a generation. Awareness of the public burden of SUDEP has improved in recent years, but has not been translated into communications with patients. While the checklist is being used in many places across the UK and internationally it is still not in the common professional, clinical psyche of the practising epilepsy clinician.

In this information-rich world people increasingly want to know more about their medical conditions, treatment, and their risks. This 5-10-minute risk assessment checklist serves to inform PWE about their risk factors and how some lifestyle changes, for example medication compliance and surveillance at night, can have a positive impact on mitigating their individual risk of SUDEP. It provides documentary evidence for the clinicians on the impact of the treatment plan over a period of time and demonstrates effective clinical governance while enhancing patient safety. ${ }^{13}$

While there is no proven intervention or national surveillance of epilepsy mortality, the safety checklist is a simple and practical tool that can be used to demonstrate effective clinical and corporate governance while enhancing patient safety. It can also help give some assurance to bereaved families that every effort was made to reduce risk and prevent a fatality.

Although the safety checklist was developed for SUDEP risk, factors such as non-adherence, depression, and substance misuse appear to closely overlap with the findings on risk from literature on all causes of epilepsy mortality. ${ }^{14-16}$

\section{EPSMON: A DIGITALISED MOBILE APP}

It lends itself to a variety of templates such as paper A4 sheets, Microsoft Excel ${ }^{\circledR}$ spreadsheets to monitor risk longitudinally, telehealth services, and has been developed into a patient self-monitoring mobile app: EpSMon. EpSMon looks to incorporate key evidence-based risk factors with a view to empowering service users to monitor their own risk and has been launched as a patient self-monitoring mobile app for adults in association with Plymouth University and SUDEP Action. The advantage of using patient-owned digital platforms backed onto secure servers is that it helps collect suitable datasets to enable well-powered studies into these risk factors. The checklist and EpSMon are part of the new Epilepsy Commissioning Tool kit (http://www.epilepsytoolkit.org.uk/). In addition to improving care it could also provide a cost-effective model to fill the safety void left from the recent removal of the QOF in epilepsy in primary care. This template of joint partnership of risk between patients and primary care could be a prototype for other chronic disorders that could adopt such evidenced-based e-approaches.

Registration for further information on EpSMon and a downloadable version of the SUDEP and seizure safety checklist are available online (www.sudep.org).

\section{Rohit Shankar,}

Consultant Neuropsychiatrist, Cornwall Partnership NHS Foundation Trust (CFT) and Honorary Clinical Associate Professor, Exeter Medical School, Truro.

\section{Craig Newman,}

Research Fellow, Plymouth Medical School,

Plymouth.

\section{Brendan McLean}

Lead Consultant Neurologist, Royal Cornwall Hospital Trust, Truro.

\section{Tamsyn Anderson,}

GP, Newquay Health Centre, Newquay; Clinical Lead, NHS Kernow Commissioning.

\section{Jane Hanna OBE}

CEO, SUDEP Action, Wantage.

\section{Acknowledgements}

The authors thank the SUDEP Action, Kt's Fund, Cornwall Coroner Dr Emma Carlyon and her Office, Dr David Cox, CFT and Mrs Caryn Jory, CFT.

\section{Provenance}

Commissioned; not externally peer reviewed.

DOI: 10.3399/bjgp15X686413

\section{ADDRESS FOR CORRESPONDENCE}

\section{Rohit Shankar}

Cornwall Partnership NHS Foundation Trust, Chy Govenek, Threemilestone Industrial Estate, Truro TR4 9LD, UK.

\section{E-mail: rohit.shankaranhs.net}

\section{REFERENCES}

1. Terra VC, Cysneiros R, Cavalheiro EA, Scorza FA. Sudden unexpected death in epilepsy: from the lab to the clinic setting. Epilepsy Behav 2013; 26(3): 415-420.

2. Devinsky 0 . Sudden, unexpected death in epilepsy. NEJM 2011; 365(19): 1801-1811.

3. Thurman DJ, Hesdorffer DC, French JA. Sudden unexpected death in epilepsy: assessing the public health burden. Epilepsia 2014; 55: 1479-1485

4. Hanna NJ, Black M, Sander JWS, et al. The National Sentinel Clinical Audit of EpilepsyRelated Death. Epilepsy - death in the shadows. Norwich: The Stationery Office, 2002.

5. National Institute for Health and Care Excellence. The epilepsies: the diagnosis and management of the epilepsies in adults and children in primary and secondary care. CG137. London: NICE, 2012.

6. Waddell B, McColl K, Turner C, et al. Are we discussing SUDEP? A retrospective case note analysis. Seizure 2013; 22(1): 74-76.

7. Smith P. Avoiding premature death in epilepsy [rapid response]. www.bmj.com/content/350/ bmj.h718/rapid-responses laccessed 27 Jul 2015).

8. Xu Z, Ayyappan S, Seneviratne U. Sudden unexpected death in epilepsy (SUDEP): what do patients think? Epilepsy Behav 2015; 42: 29-34.

9. Shankar R, Cox D, Jalihal V, et al. Sudden unexpected death in epilepsy (SUDEP): development of a safety checklist. Seizure 2013, 22 (10): 812-817.

10. Brown S, Shankar R, Cox D, et al. Clinical governance: risk assessment in SUDEP. Clinical Governance: an International Journal 2013; 18(4): 325-331.

11. Shankar R, Jalihal V, Walker $M$, et al. A community study in Cornwall UK of sudden unexpected death in epilepsy (SUDEP) in a 9-year population sample. Seizure 2014; 23(5): 382-385

12. Beran RG. SUDEP revisited - a decade on: have circumstances changed? Seizure 2015; 27: 47-50.

13. Shankar R. SUDEP - are we as safe as we can be? http://www.sudepglobalconversation. com/\#!shankar/c22s5 (accessed 5 Aug 2015).

14. Ridsdale L, Charlton J, Ashworth M, et al. Epilepsy mortality and risk factors for death in epilepsy: a population-based study. $\mathrm{Br} J \mathrm{Gen}$ Pract 2011; 61(586): 271-278

15. Ostler A, Cousins S, Ridsdale L. The causes of death in epilepsy: a systematic review. SUDEP Action January 2015. https://www.sudep.org/ files/sudepaction/the_causes_of_death_in_ epilepsy_0.pdf (accessed 5 Aug 2015).

16. Ridsdale $L$. Avoiding premature death in epilepsy. BMJ 2015; 350: h718. 